\title{
Quantum Biological Thermodynamics with Finite Speed of the Cardio-Pulmonary System \\ III-Comparison between stationary states and processes with or without quantum jump for a family members
}

\author{
BOGDAN BORCILA ${ }^{1 *}$, STOIAN PETRESCU ${ }^{1}$, MONICA COSTEA ${ }^{1}$, VALERIA PETRESCU ${ }^{1}$, ROMI BOLOHAN ${ }^{2}$ \\ 'University Politehnica of Bucharest, 313 Splaiul Independentei, 060042, Bucharest, Romania \\ 2Emergency Clinical Center for Cardiovascular Diseases Dr. Constantin Zamfir, Clinic of Cardiology, Electrophysiology and \\ Arrythmology, 134 Calea Plevnei, 010242, Bucharest, Romania
}

\begin{abstract}
The paper presents studies based on measurements of the Fundamental State Parameters $\left(F_{H^{\prime}} F_{L^{\prime}}, R_{f}\right.$ and $N$, the quantum interaction number between the Heart and the Lungs) of the Cardio-Pulmonary System by persons belonging to a family, based on established protocols, for a more complete knowledge of its functioning. Thus, the persons are different in terms of age, sex and physical characteristics (weight, height, and lifestyle), they have parental or cohabiting statuses (mother-son, father-son, husband-wife). They perform the same activities or have different concerns with a higher or lower Power consumption. The diagrams constructed using the Fundamental State Parameters in Quantum Biological Thermodynamics with Finite Speed (QBTFS) allow the study of Stationary Quantum States and the interaction Processes between them (with or without Quantum J ump), which provides very important data on the functional characteristics of the Cardio-Pulmonary System for each person. The information obtained within QBTFS of the CardioPulmonary System is particularly useful for the personalized design of the Hearts and artificial Lungs according to the physical and physiological particularities of different patients.
\end{abstract}

Keywords: Fundamentals State Parameters, Cardio-Pulmonary System, Stationary States, Quantum Biological Thermodynamics with Finite Speed, Processes with or without Quantum J ump.

The Quantum Biological Thermodynamics with Finite Speed (QBTFS) [1], developed as an extension of Thermodynamics with Finite Speed (TFS) [1-5] to the Cardio-Pulmonary System (CPS) is based on the Fundamentals State Parameters and on the two new concepts discovered: Stationary States and Processes between Stationary States. An important objective in the construction of QBTFS was to find the processes equations between Stationary States from the human CardioPulmonary System. These can be obtained similarly to those of simple Processes (isothermal, isometric, isobaric, and polytrophic), in the Classical Reversible Thermodynamics, using the quantified fundamental formula on Heart-Lungs interaction for Stationary States in CPS relating the Frequency of the Heart, $F_{H}$ and of Lungs, $F_{L}$ :

$$
F_{H}=F_{L} \cdot(2+N / 4)
$$

where $N$ is an integer number that we called Quantum Number of the interaction between the Heartand Lungs in any Stationary State, in any healthy person. It resulted that if a person does not achieve easy and quite fast (1-2 minutes) such a State, eq. (1) is not validated for she or he, which means this person may have already illness or will have it in the future.

The explanation for eq. (1) is based on the Synergetic interaction between the two oscillators (the Heart and the Lungs), which tend to organize themselves in optimal operation.

After the invention of Advanced Synergetics by Herman Hacken [6], and this subject was resumed by Adelina
Georgescu [7], others researchers [8] studied and agreed that the interaction between two oscillators of any origin (mechanical, electrical, chemical, biological etc.) tends to self-organize so that a higher degree of order to be obtained.

This superior degree of order is expresses by formula (1). People who are healthy tend to respect this formula which means they have a high degree of order in them, but the people who do not (anymore) respect this formula have a tendency to get ill or have already an illness, which introduces a degree of disorder in the interaction between Heart and Lungs. As a consequence of this Selforganization, for healthy people, the two previously mentioned Frequencies $\left(F_{H}\right.$ or/and $\left.F_{L}\right)$ may be constant (for minutes, tens of minutes or even hours) in what its called Stationary Quantum States (SQS), when laying, sitting on a chair, walking, or doing repetitive physical work etc. In addition to that, after a certain action the Stationary State is changed, also in an organized way in agreement with the formulas presented in paper [9].

Two points corresponding to different the successive Stationary States can be connected resulting the Process lines similar with the lines illustrating Reversible Processes in Classical Reversible Thermodynamics (CRT) diagrams, such as $p-V, T-S, h-s$ etc., generally used in Thermal Machines study and design.

Eq. (1) can be applied to the successive Stationary Quantum States, representing the initial and final states of a process. As in CRT, three equations of the human CardioPulmonary System will result, when a State Parameter is kept constant during each corresponding Process (representing the passage from one Stationary State to 
another). These equations are: Iso-Heart-rhythm ( $F_{H}=$ constant), Iso-Lungs-rhythm ( $F_{L}=$ constant $)$ and IsoQuantum Number of the Heart-Lungs interaction ( $N=$ constant) [9]. The general process corresponding to the Polytrophic one in Classical Reversible Thermodynamics is introduced by the polytrophic factor given by the slope of the process line, $\mu$. This it is defined as the ratio between change of the Quantum Number between the two states (initial and final) and the change of the Frequency of the Lungs (within a Polytrophic processes all parameters of Stationary States: $F_{L^{\prime}}, F_{H^{\prime}} N$ are changing) [1].

Another fundamental concept is the ratio between the two frequencies:

$$
R_{f}=F_{H} / F_{L}=(2+N / 4)
$$

which is the interaction State parameter between the two subsystems, the Heart and the Lungs.

The paper presents a comparison between Stationary States and Processes in the Cardio-Pulmonary system corresponding to different positions and activities of 3 persons, represented in the 6 diagrams discovered in the frame of Quantum Biological Thermodynamics with Finite Speed, namely:

$$
\begin{gathered}
F_{H}=f_{1}\left(F_{L}\right), F_{L}=f_{2}\left(F_{H}\right), R_{f}=f_{(}\left(F_{L}\right), R_{f}=f_{4}\left(F_{H}\right), \\
N=f_{5}\left(F_{H}\right), N=f_{6}\left(F_{L}\right)
\end{gathered}
$$

They are also presented very interesting correlations between the changes of $\mathrm{O}_{2}$ percentage in the blood, changes of Heart Frequency $F_{\mu \prime}$, changes of Lungs Frequency, $F_{d}$, and changes of the Frequencies ratio, $R_{f}$ and $N$ (the Quantum Number) as functions of the State number of the Cardio-Pulmonary System.

\section{Experimental part}

Diagrams of Stationary States and Processes of the CardioPulmonary System of people having different degrees of kinship or living together

In this paper we study comparatively the Stationary States and Processes of the Cardio-Pulmonary System for 3 persons (BB, BDI and $B D$ ) different as age, kindred or who live together, based on the 6 diagrams of the Quantum Biological Thermodynamics with Finite Speed. The 3 persons measured $F_{4}$ and $F$. Frequencies in several positions during one day, from awaking to sleep, after

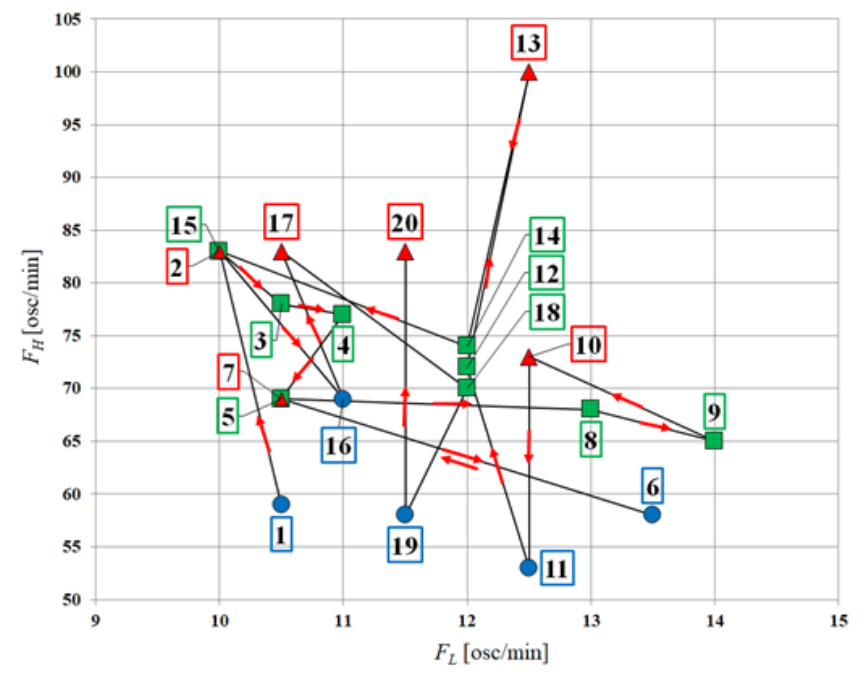

various activities involving an average energy consumption (breakfast, lunch and dinner, physical and mental work, alternating with periods of relaxation and solving personal hygiene problems). Based on these measurements, the 6 diagrams of the QBTFS were plotted. The diagrams invented in the QBTFS [10], based on equations (3) for the $\mathrm{BB}, \mathrm{BDI}$ and $\mathrm{BD}$ persons, are shown in figures $1-3,4-6$ and respectively 7-9.

The Stationary States and Processes of the CardioPulmonary System in figures 1 to 9 were represented based of the measured State Parameters values, $F_{\mu}$ and $F_{l}$, of the percentage of Oxygen in the blood tissue and the calculated factors - $R_{f}[-], N[-]$ and $\mu[\mathrm{min}]$.

These diagrams show that the BB, BDI and BD persons' Cardio-Pulmonary Systems function within normal limits, i.e., they easily reached Stationary States and the Quantified Fundamental Formula for Heart-Lungs interaction is valid. In the diagrams of figures 1-3 (for BB), several process lines are parallel, therefore they have the same Slope. Processes with such characteristics may be named as isoSlopes. One can identify:

- Iso-Rhythm Proceses ( $F=$ constant): 10-11, 19-20;

- Iso-Slope, Polytropic Process ( $\mu=$ constant): $\mu_{2-3}$ and $\mu_{17-18}=-6 ; \mu_{5-66^{\prime}} \mu_{6-7}$ and $\mu_{8-9}=-3 ; \mu_{11-12}$ and $\mu_{16-17}=-14 ; \mu_{12-13}$ and $\mu_{13-14}=16$ [min];

- other Processes with the same Slope are: $\left(\Delta F_{1} / \Delta F_{H}\right) 5$ 6 and $6-7=3 / 11 ; 10-11$ and $19-20=0 ;\left(\Delta N / \Delta F_{t}\right) 5-6$ and $6-$ $7=9 / 11 ; 4-5$ and $18-19=1 / 4 ; 8-9$ and $14-15=1 ;\left(\Delta F_{H} / \Delta F_{L}\right)$ $5-6$ and $6-7=11 / 3$.

The diagrams in figure 3 shows significant correlations between changes in blood $O_{2}$ percentage, Heart rate $F_{H \prime}$ pulmonary Frequency $F_{f}$, ratio $R_{f}$ and $N$ as a functions of the State Numbers of the Cardio-Pulmonary System (1, 2, $3, \ldots, 20)$, during elementaryand complex Processes. In all 20 States, the percentage of 0 , was within the normal range (over $95 \%$ ), with most of them equal to or greater than $96 \%$. In one State it reached the maximum value (99\%).

The analysis of the diagrams shows a good correlation of the State Parameters of the Cardio-Pulmonary System, which maintains the percentage of $O$ in the bloodstream within the proper limits for the optimal functioning of the vital Processes in the body [9-19].

At the same time, the diagrams in figure 3 reveals an optimal correlation between the Slope of the Polytrophic Process and the change of position (from horizontal to vertical or from sitting on a chair to standing, for example) or other Processes generated by different activities.

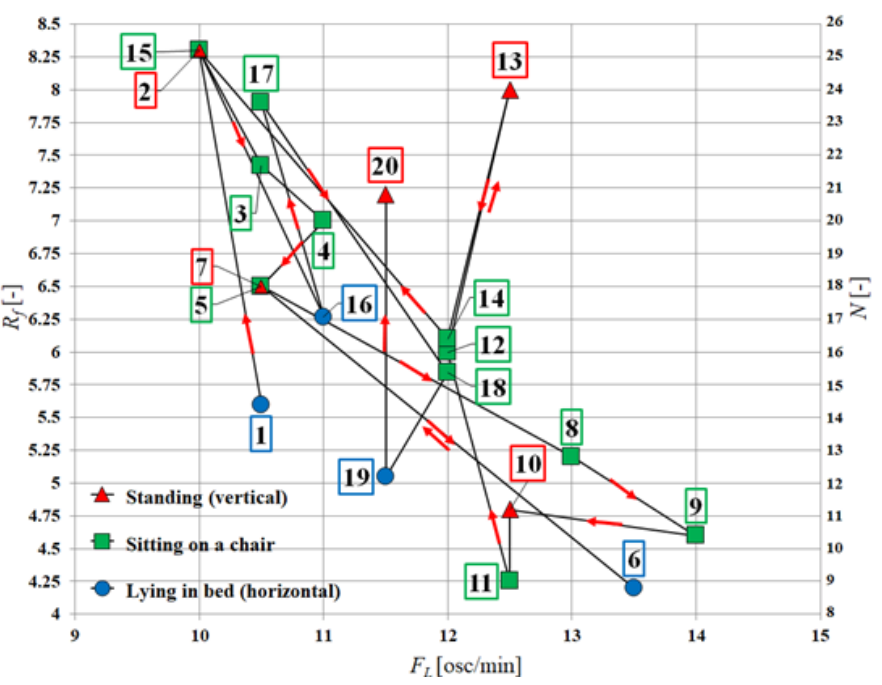

Fig. 1. The diagrams $F_{H^{\prime}} R_{f}$ and $N=f\left(F_{L}\right)$ (for BB) 

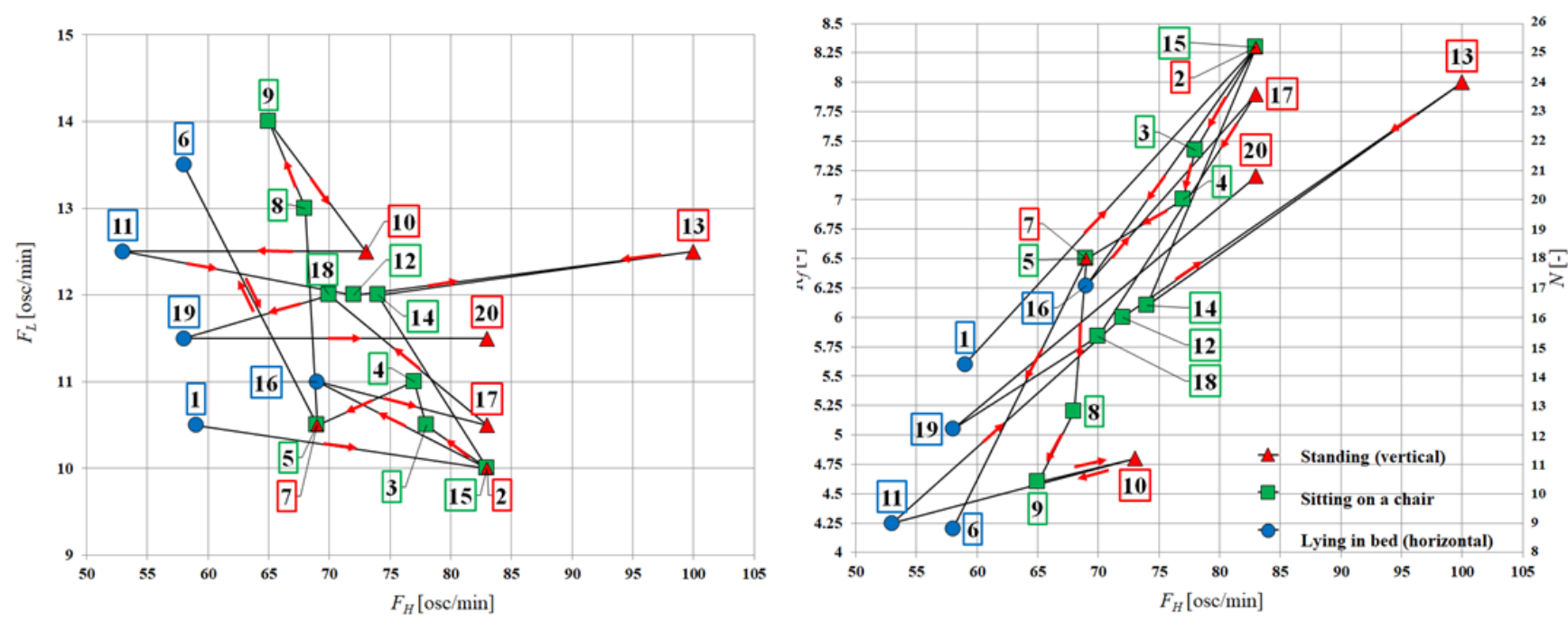

Fiq. 2. The diagrams $F_{\iota}, R_{f}$ and $N=f\left(F_{\iota}\right)$ (for $\mathrm{BB}$ )
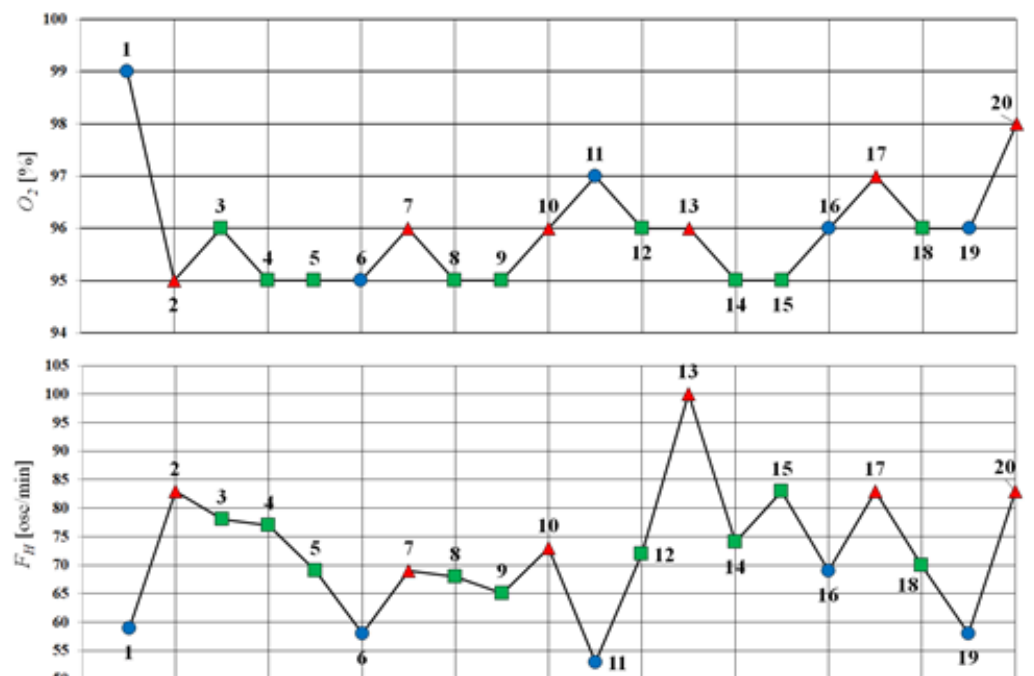

Fig. 3. The diagrams that represent the percentage of $O_{2^{\prime}} F_{H^{\prime}} F_{L^{\prime}}$ Slope $\mu, R_{f}$ and $N=f$ (State Number) (for $\mathrm{BB})$.
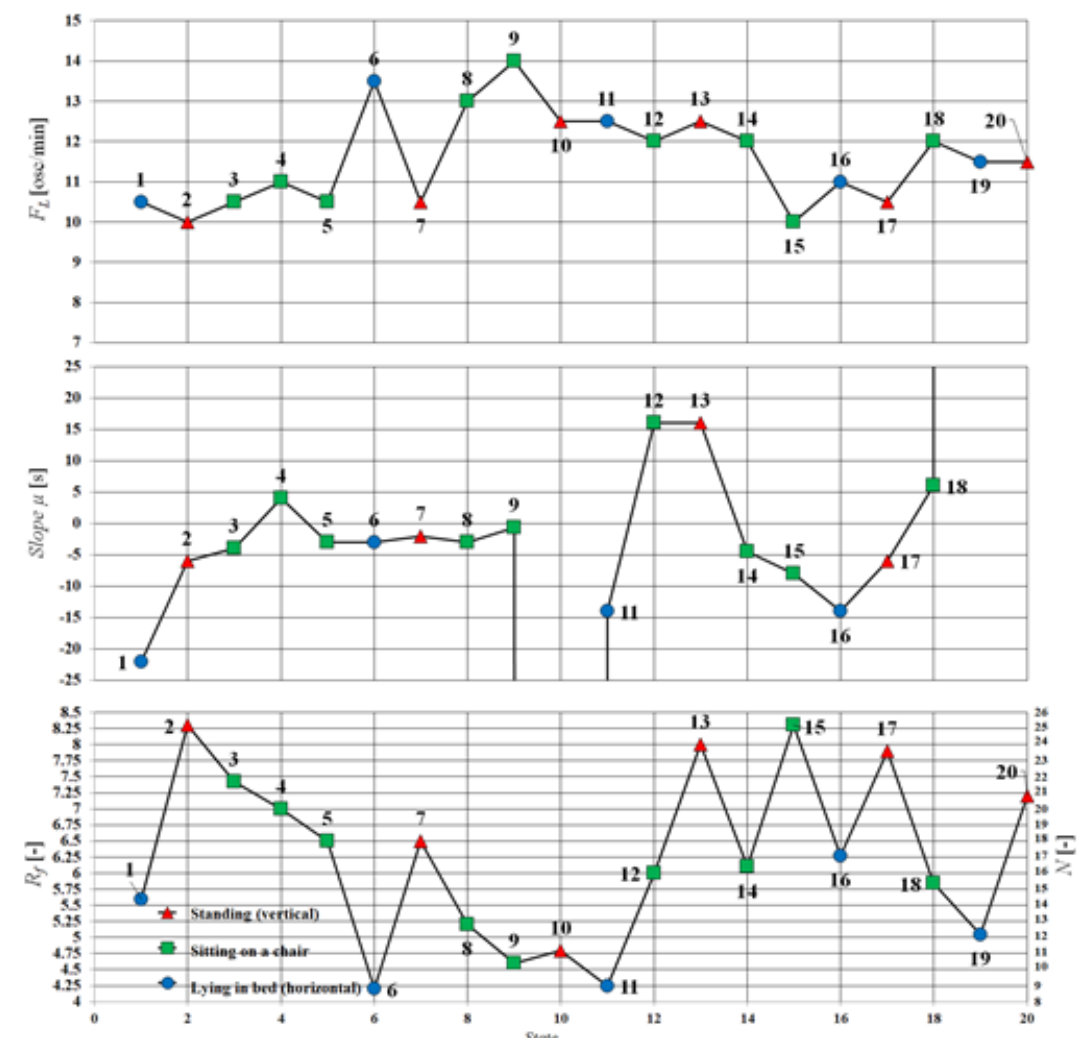

The BB person practiced a lot of sports, has the optimum height-weight ratio, does not smoke and has balanced nutrition, so the optimal gas exchange Processes in the Lungs is performed at low Frequency variations, $F_{L^{\prime}}$ between 10 and $14 \mathrm{osc} / \mathrm{min}$, and $N$ ranges from 9 to 25 , indicating well-developed Lungs and great effortcapacity. Also, given the peculiarities of this person, the Heart rate $F_{H}$ is within normal range (53-83 osc/min), with one 
exception of $100 \mathrm{osc} / \mathrm{min}$. when the body's effort was higher but with $F$ within normal range ( $12.5 \mathrm{osc} / \mathrm{min}$ ).

Study of the diagrams in figures 4-6 (for BDI) highlights several parallel Process Lines, which therefore have the same Slope (Iso-Slopes):

- Iso-Rhythm ( $F=$ constant): 5-6, 10-11, 11-12;

- Iso-Slope, Polytrophic Process ( $\mu=\Delta N / \Delta F_{L}$ constant): $\mu_{1-2}$ and $\mu_{19-20}=0 ; \mu_{4-5}$ and $\mu_{16-1}=-6 ; \mu_{8-9}$ and $\mu_{17-18}=-4 ; \mu_{9-10}$ and $\mu_{14-15}=-2$ [min];

- other Processes with the same Slope are: $\left(\Delta F_{,} / \Delta F_{H}\right) 5$ $6,7-8,10-11$ and $11-12=0 ; 6-7$ and $17-18=-1 / 5 ;\left(\Delta N / \Delta F_{H}\right)$ 6-7 and 16-17=3/5; $12-13$ and 13-141/12; $\left(\Delta F_{H} / \Delta F_{L}\right)$ 6-7 and $17-18=-5$.

The diagrams in figure 6 reveals significant correlations betw een variations in the percentage of $\mathrm{O}_{2}$ in the blood of the person $\mathrm{BDI}$, Heart rate $F_{H^{\prime}}$ pulmonary Frequency $F_{{ }^{\prime}}$, ratio of $R_{f}$ and $N$ Frequencies as functions of the States of the Cardio-Pulmonary System $(1,2,3, \ldots, 20)$ during the various elementary and complex Processes.

The percentage of $\mathrm{O}_{2}$ was within the normal range (over $95 \%$ ) in the 20 States, most (16 States) being equal to or greater than $96 \%$. In one of the States reached the maximum value ( $99 \%)$, and in another 4 , the percentage of $\mathrm{O}_{2}$ was $98 \%$. The study of the diagrams reveals that the States Parameters $F_{\mu \prime} F_{l}, R_{f}$ and $N$ of the two subsystems (the Heart and the two Lungs) within the Cardio-Pulmonary System are well correlated. This ensures that the percentage of $\mathrm{O}_{2}$ in the blood is maintained in a set of

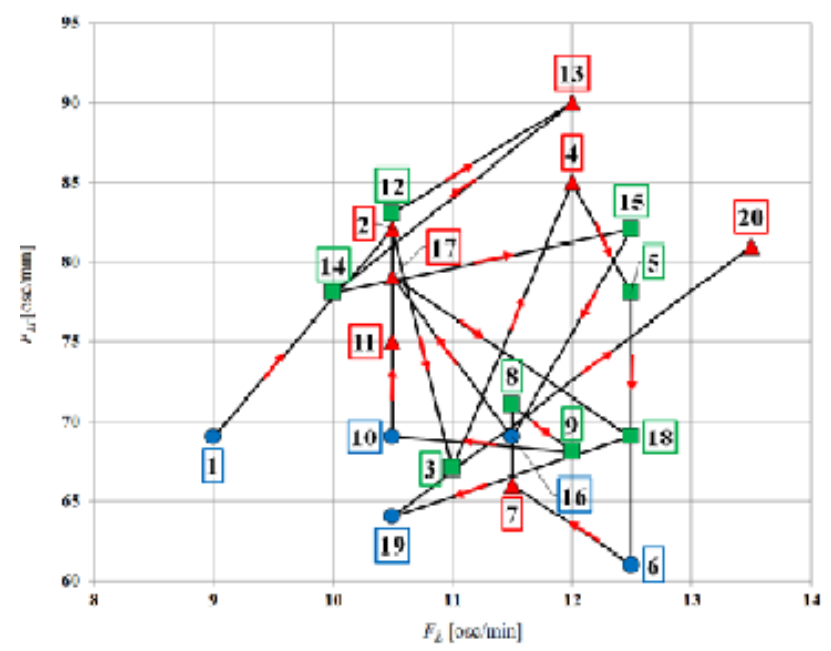

values that allow the vital Processes in the body to function optimally [9-19]. The analysis of the diagrams in figure 9 also points out that there is a very good correlation between the Slopes of the Polytrophic Processes, $\Delta N / \Delta F_{1}$, and the changes of the position (from the horizontal to seating or directly on the vertical etc.) or other Processes generated by different activities. The BDI person has also practiced a lot of sports, does not smoke, has a balanced nutrition and, although in terms of height-weight ratio, has a slight tendency towards obesity, the Processes of optimal gas exchange in the two Lungs are made at low variations of the Frequency $F_{1}$, between 9 and $13.5 \mathrm{osc} / \mathrm{min}$.

Also, considering the physical and behavioral characteristics of the BDI person, $F_{\mu \prime}$, Heart rate in the 20 states is also within normal range ( $61-90 \mathrm{osc} / \mathrm{min})$ and $N$ ranges from 12 to 24 , therefore the BDI has a welldeveloped Lung System and great effort resistance.

Analysis of diagrams in figures 7-9 (for $B D$ ) reveals some parallel Process Lines (with the same Slope), namely:

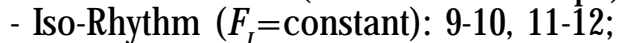

- Iso-Slope, Polytrophic Process ( $\mu=\Delta N / \Delta F_{L}=$ constant): $\mu_{1-22^{\prime}} \mu_{18-19}$ and $\mu_{19-20}=0 ; \mu_{4.5}$ and $\mu_{16-17}=-6 ; \mu_{8-9}$ and $\mu_{3-14}=-4$; $\mu_{10-11}^{1-21}$ and $\mu_{17-18}=-2$ [min];

- other Processes with the same Slope: $\left(\Delta F_{/} / \Delta F_{H}\right)$ 2-3 and 8-9; 3-4 and 4-5=3/10; 7-8 and 9-10=3/2; 10-11 and $11-12=0 ;\left(\Delta N / \Delta F_{t}\right) 1-2$ and $19-20=0 ; 6-7$ and $16-17=3 / 5$; $\left(\Delta F_{H} / \Delta F_{L}\right)$ 2-3 and 8-96; 3-4 and 4-5=10/3; 7-8 and 9-102/ 3.

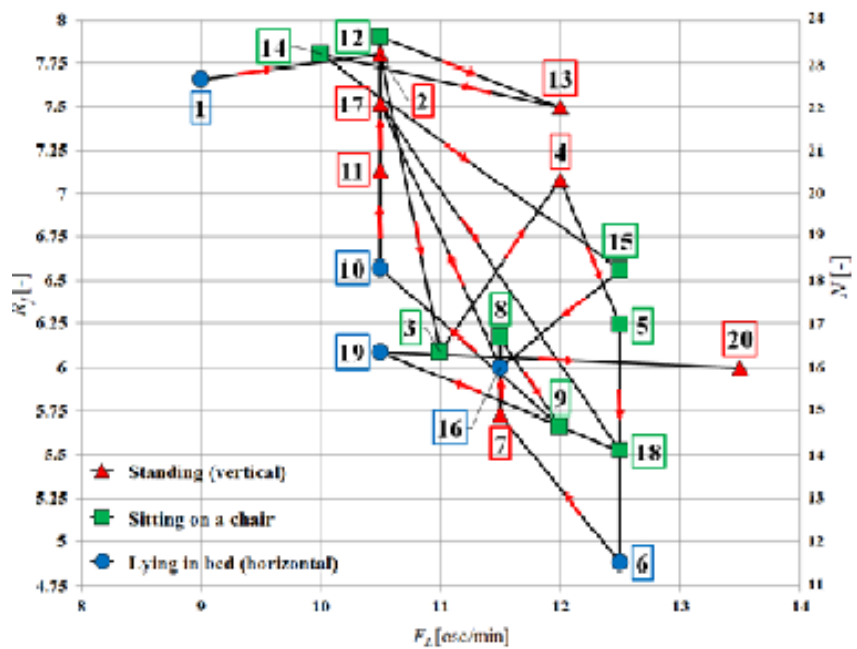

Fig. 4. The diagrams $F_{H^{\prime}} R_{f}$ and $N=f\left(F_{L}\right)$ (for $\mathrm{BDI}$ )
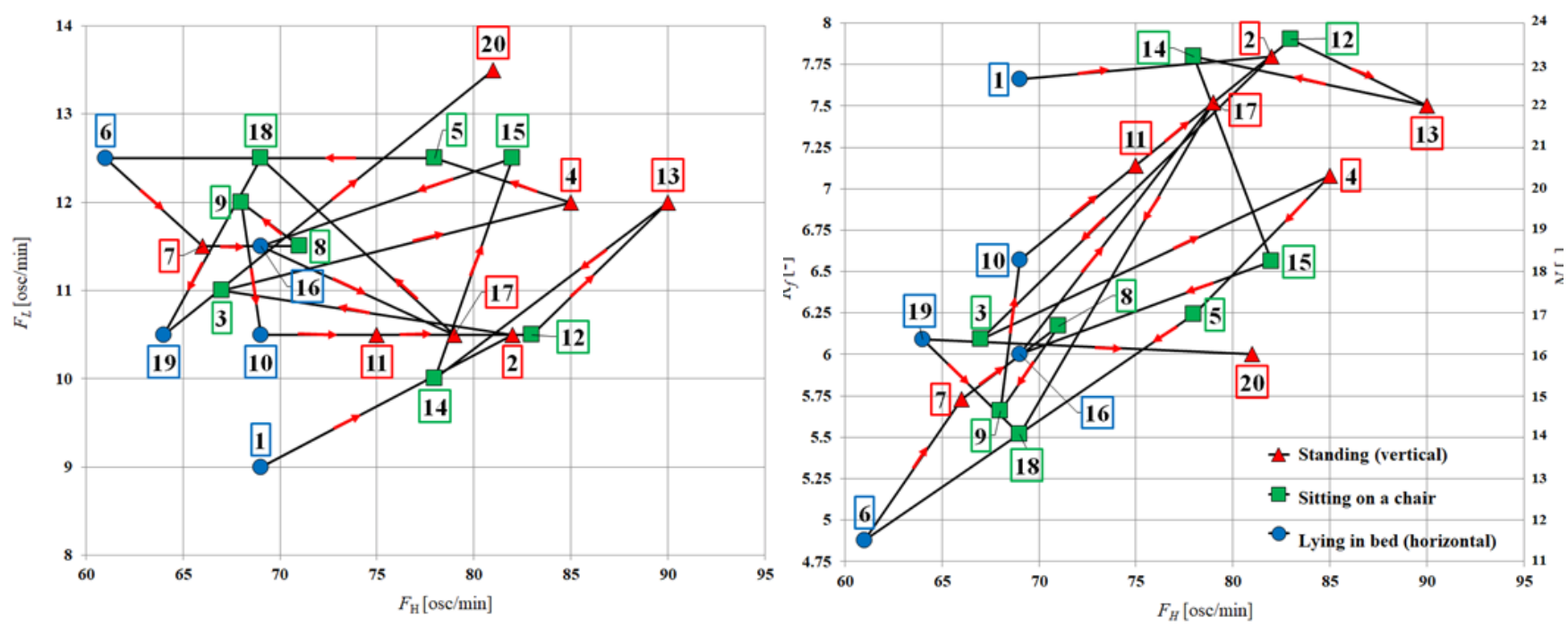

Fig. 5. The diagrams $F_{L^{\prime}} R_{f}$ and $N=f\left(F_{H}\right)$ (for BDI) 

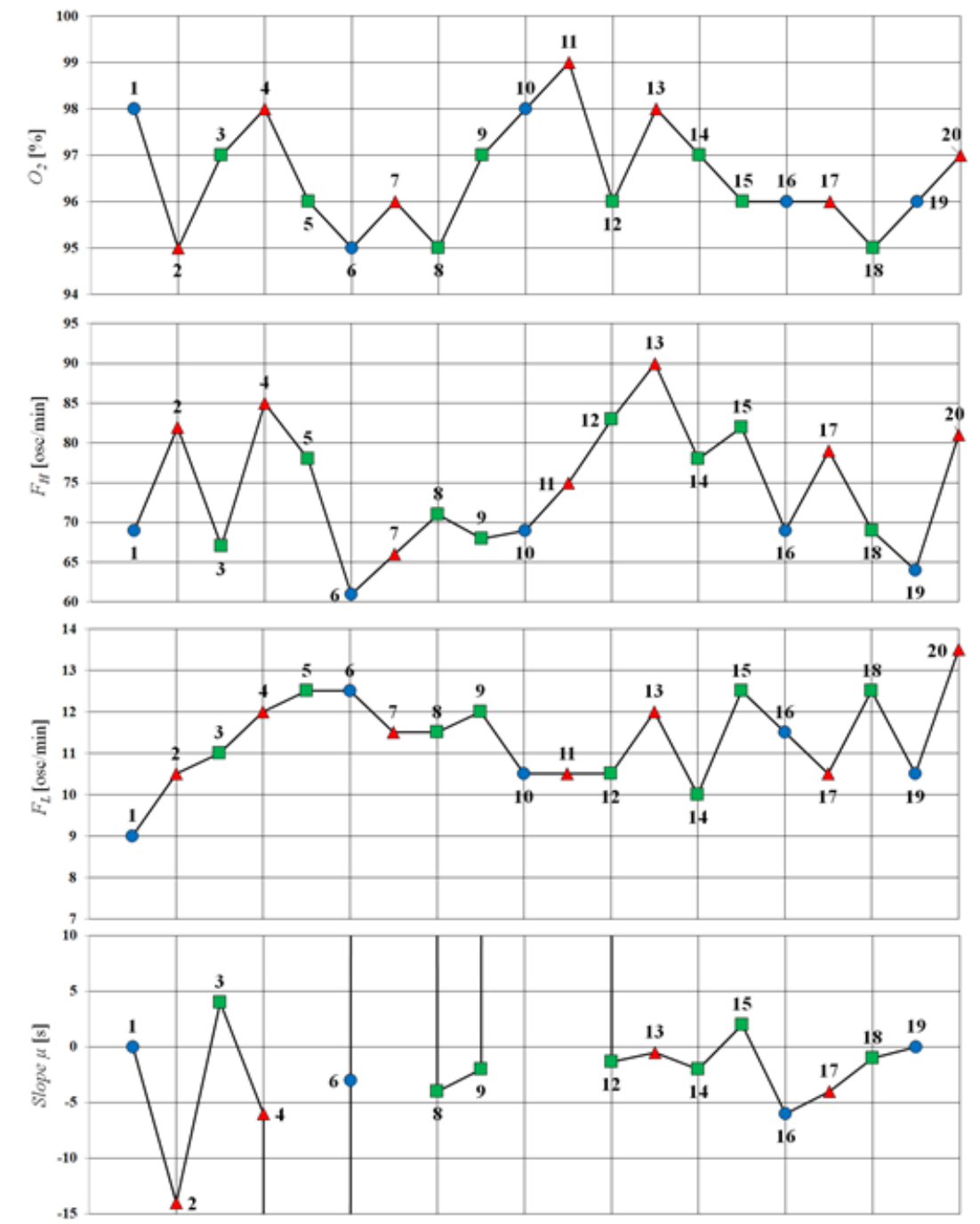

Fig. 6 . The diagrams that represent the percentage of $O_{2^{\prime}} F_{\mu^{\prime}} F_{L}$ the Slope $\mu, R_{f}$ and $N=f$ (State Number) (for BDI).
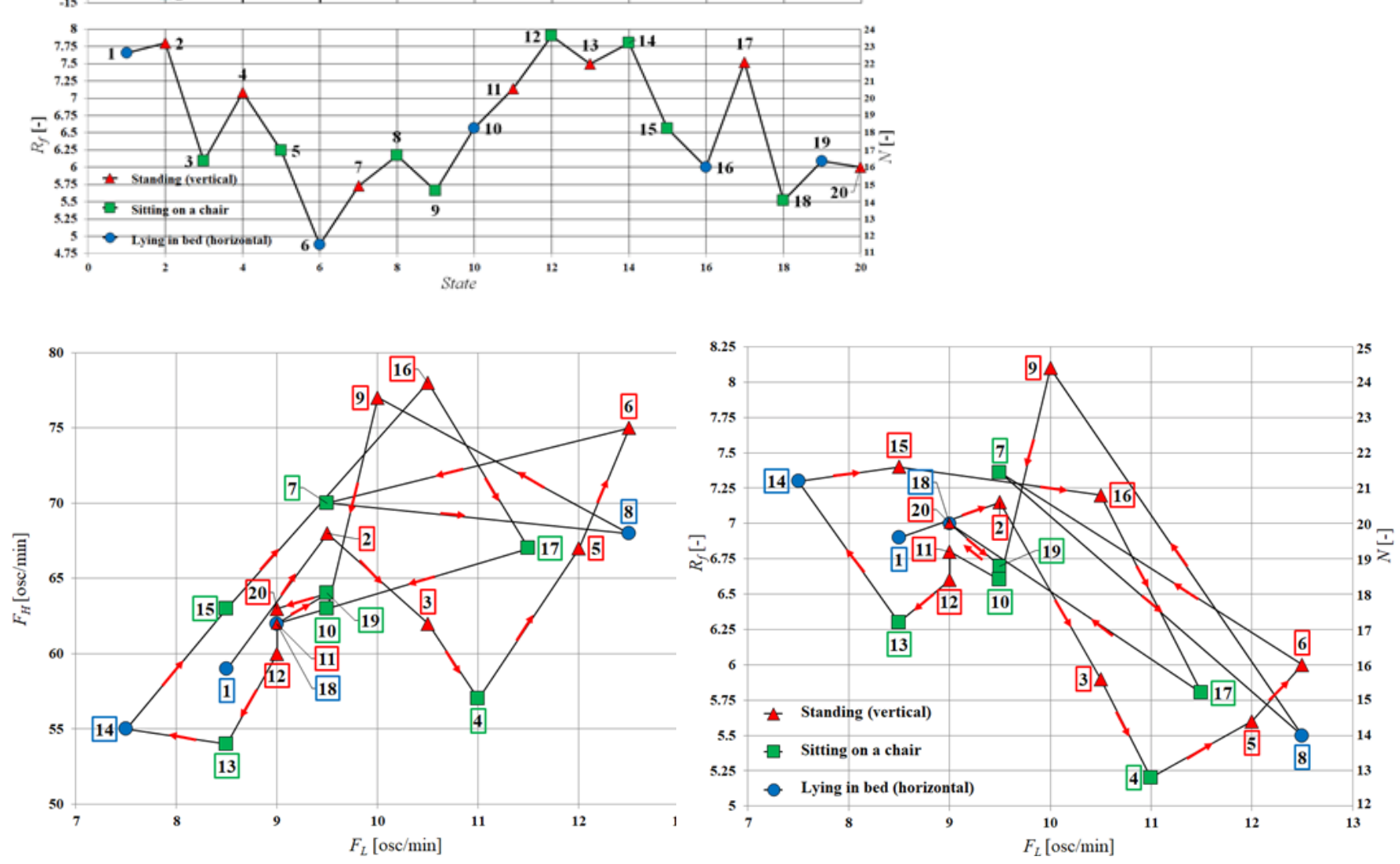

Fig. 7. The diagrams $F_{H^{\prime}} R_{f}$ and $N=f\left(F_{L}\right.$ ) (for BD) 

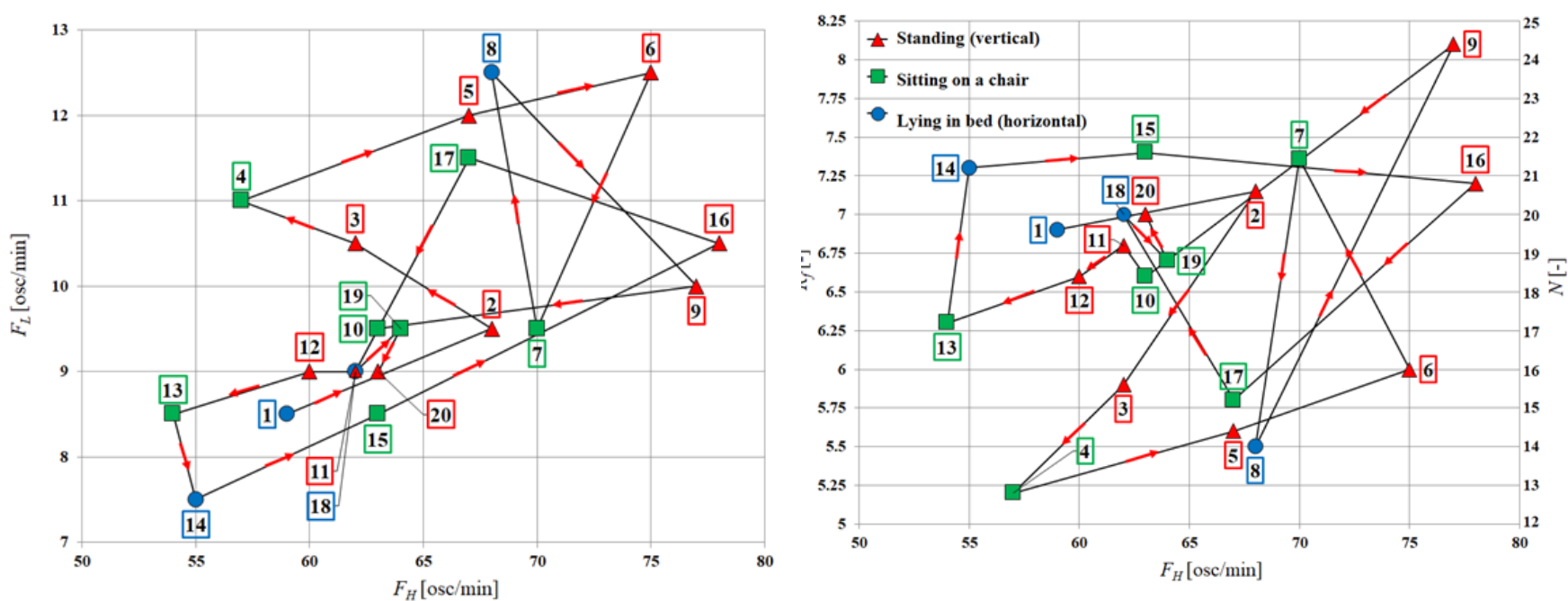

Fig. 8. The diagrams $F_{L^{\prime}} R_{f}$ and $N=f\left(F_{H}\right)$ (for BD)
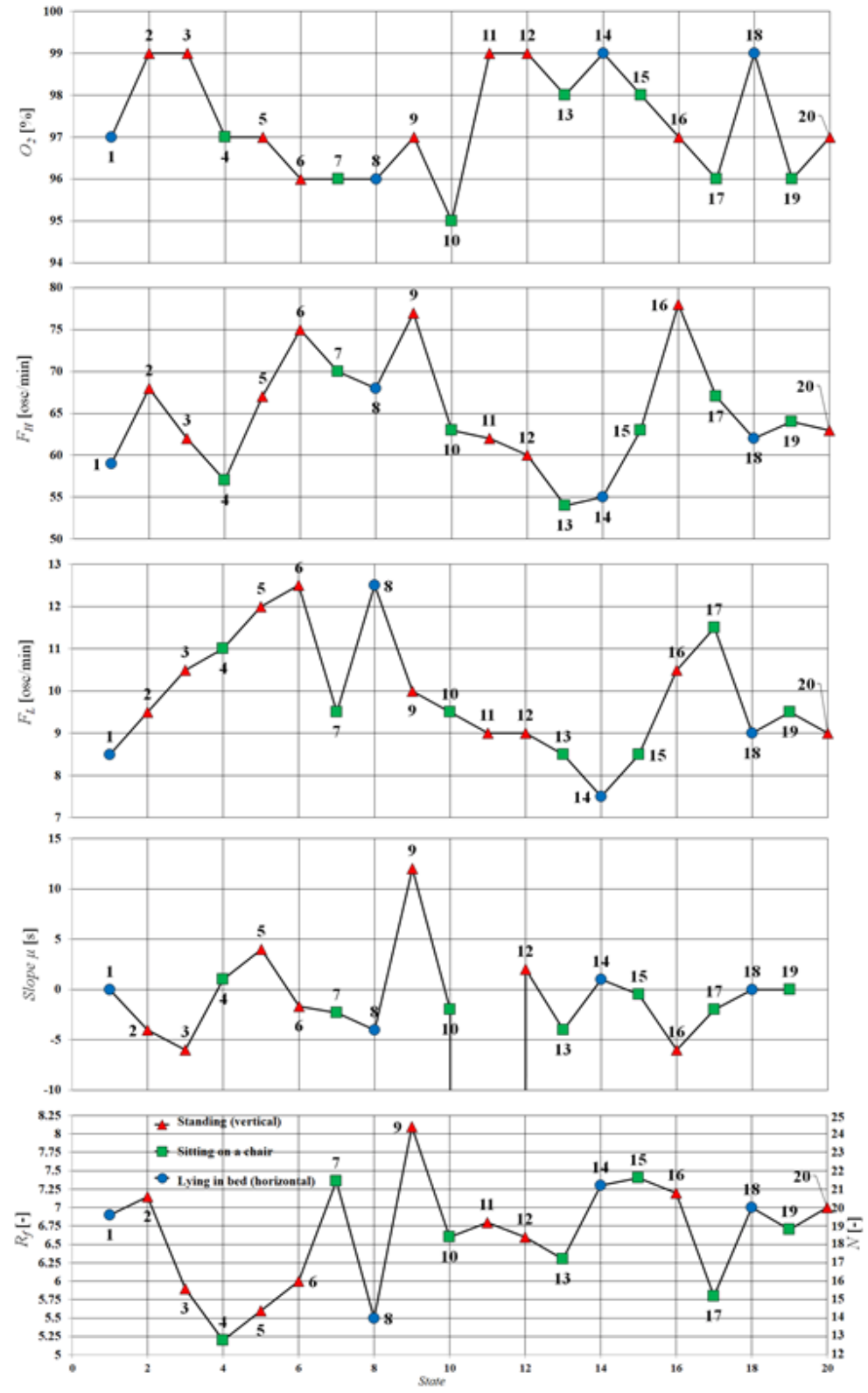

Fig. 9. The diagrams that represent the percentage of $O_{2^{\prime}} F_{H^{\prime}}, F_{L^{\prime}}$ Slope $\mu, R_{f}$ and $N=f($ State Number) (for BD)

The correlations between changes in the percentage of $O$, in blood tissue, Heart rate $F_{\mu \prime}$ Lungs Frequency $F_{\text {, }}$, ratio $R_{f}^{2}$ and $N$, as functions of the State Numbers of the CardioPulmonary System $(1,2,3, \ldots, 20)$, during the elementary Processes represented in the diagrams in figure 9, are conclusive for the general health of the BD person. The percentage of $\mathrm{O}_{2}$ was within the normal range in all States (over 95\%). In most of them, they had values equal to or greater than $97 \%$. That is, in two of the States it was $98 \%$ and in 6 had the maximum value (99\%). From the analysis of diagrams of figures 7-9, results the good correlation of the Cardio-Pulmonary System parameters of $F_{H^{\prime}} F_{L^{\prime}}, R_{f}$ and $N$ parameters, which ensures the variation of the percentage of $\mathrm{O}_{2}$ in the blood within the normal limits 
corresponding to optimal functioning of whole body organs [9-19]. From the study of diagrams represented in figure 9 results there is a very good correlation between the Slopes of the Polytrophic Processes and the various elementary and complex Processes generated by the activities carried out.

The BD person has practiced and practices many sporting activities, has the optimum height-weight ratio, does not smoke, has balanced nutrition and is clumsy, having the more developed muscular system on the left side. The study of the diagrams reveals that the gas exchange Processes in the Lungs are carried out in optimal conditions with a limited variation of the $F$ Frequency, ranging from 8.5 to $12.5 \mathrm{osc} / \mathrm{min}$, including in case of higher physical effort. The Quantum Number $N$ has the range of variation 14-24, therefore BD has well-developed Lung volumetric capacity and high effort resistance. Given the particularities of this person presented in the previous paragraph, the Heart rate $F_{H}$ is also within normal range (54-78 osc/min), which is consistent with its balanced lifestyle.

\section{Conclusions}

The comparative study of the diagrams based on the State Parameters of the BB, BDI and BD persons allows to highlight some characteristic elements for which the nature of the relationships, the lifestyle, the diet, the existence or the absence of some vices etc. could be determinant. Note that $\mathrm{BB}$ has kinship relationships with both $B D I$ and $B D$. At the same time, $B D$ and $B D I$ are not relatives but have family relationships for over 30 years.

Thus, the 3 persons, practicing a lot of sports, having a balanced life without excesses in nutrition or others, have values of Lungs Frequencies, $F_{\text {, }}$, very close: BB (10-14 osc/ $\mathrm{min}), \mathrm{BDI}(9-13.5 \mathrm{osc} / \mathrm{min})$ and $\mathrm{BD}(8.5-12.5 \mathrm{osc} / \mathrm{min})$. Similarly, Heart Frequencies, $F_{t \prime}$, are very close as values and fall within normal limits: $B B^{\prime \prime}$ (53-83 osc/min, in one of the State having $100 \mathrm{osc} / \mathrm{min}$, in a larger effort high, but with $\left.F_{1}=12.5 \mathrm{osc} / \mathrm{min}\right), \mathrm{BDI}(61-90 \mathrm{osc} / \mathrm{min}), \mathrm{BD}$ (54-78 $\mathrm{osc} / \mathrm{min}$ ). At the same time, the variation domains of the Quantum Number $N$ are very close: BB (9-25), BDI (1224), $B D$ (14-24), which are consistent with their lifestyle.

The Cardio-Pulmonary System of each person (BB, BDI and BD) easily reaches Stationary Quantum States after various processes, and the correlations between changes in $\mathrm{O}_{2}$ percentage of blood tissue, Heart rate, $F_{H^{\prime}}$ pulmonary Frequency, $F_{1}$, ratio $R_{f}$ of them and $N$ as functions by the States Number are optimal. The study of the diagrams of figures $1,2,4,5,7$ and 8 shows a good correlation of the State Parameters of the Cardio-Pulmonary System, $F_{H^{\prime}} F_{L^{\prime}}$ $R_{f}$ and $N$, for each person, which maintains the percentage of $O$ of the blood in normal limits (between 95 and $99 \%$ ).

Also, the diagrams in figures 3,6 and 9 highlights a very good correlation between the Slopes of Polytrophic Processes and changes in position in the various activities of the mentioned persons.

In the case of the BD and BDI persons, it was found that for different States Fundamental Parameters, more IsoSlopes of Polytrophic Processes ( $\mu=\Delta N / \Delta F_{L}$ constant) have the same value: (BDI) $\mu_{1-2}$ and $\mu_{192-20}=0 ; \mu_{4-5}$ and $\mu_{16-17} 6 ; \mu_{8}$ and $\mu_{17-18} 4 ; \mu_{9-10}$ and $\mu_{142.15} 2 ;(B D) \mu_{1-2}$ and $\mu_{19-20} 0 ; \mu_{45}$ and $\mu_{16-17} 6 ; \mu_{8-9}$ and $\mu_{13-14} 4 ; \mu_{10-11}$ and $\mu_{17-18}^{2}$ [min].

This phenomenonon could be expläined on the basis of the Synergetic Interaction between two oscillators - the Cardiac Subsystems of the BD and BDI persons - which tend to self-organize in a superior optimal functioning. As we mentioned at the beginning of this paper, the inventing of Advanced Synergetics by Herman Hacken [6], followed by the studies of a significant number of researchers [8] on this phenomenon, have led to the conclusion that the interaction between two oscillators has the tendency to self-organize in such a way that it results in a higher degree of order in the system itself.

The Heart Math Institute at Standford University [20] found that the Heart is emitting an Electromagnetic Field five thousand times more powerful than that of the brain, identical to the Electromagnetic Field around the Earth. The science of understanding the effects of the Electromagnetic Field generated by the Heart is at first, but researchers at the Heart Math Institute have determined that the information contained therein maybe vital in the unitary functioning of the human body and can affect the persons in the immediately vicinity. Also, the Electromagnetic Field of the Heart changes according to emotional States, generating Sinusoidal Electromagnetic Waves, characterized by Velocity, Wavelength and Oscillation Frequency.

The interference of two Electromagnetic Fields, each with a certain Oscillation Frequency, according to advanced Synergetics, tends to self-organize resulting a higher degree of order in the formed system (by the two fields), respectively in the relational one, as in the case of $B D$ and BDI at a time.

It is important to point out that the two persons often have moments when they have communion of thought and extra-sensorial communication, including when they are physically far from one another relative.

The basics of development Quantum Biological Thermodynamics with Finite Speed [1, 4, 9, 12-19, 21, 22] allow a deeper understanding of both normal and Pathological Processes on the functioning of human CardioPulmonary System. At the same time, they include key dates for finding ways and means for quantitative study of various techniques used in physiology and relaxation. Therefore, there are premises for the development of QBTFS to be able to contribute to the design of artificial organs according to the physiological particularities of each patient, using the Direct Method from the Thermodynamics with Finite Speed, similarly to Thermal Machines.

\section{References}

1. PETRESCU, S., COSTEA, M., PETRESCU, A.S., PETRESCU, V., From Thermodynamics with Finite Speed towards Biological Quantum Thermodynamics with Finite Speed, Proceedings of the National Conference of Thermodynamics NACOT'15, Iasi, Romania, 2015.

2. ENACHE, V., PETRESCU, S., BOLOHAN, R., Conditii de optim în sistemul Cardio-Vascular-Pulmonar obtinute în cadrul Termodinamicii Ireversibile cu Viteza Finita, I. Debitul de oxigen în functie de viteza sangelui, Rev. Chim.(Bucharest), 66, no. 9, 2015, p. 1485-1489

3. ENACHE, V., PETRESCU, S., BOLOHAN, R., Conditii de optim în sistemul Cardio-Vascular-Pulmonar obtinute in cadrul Termodinamicii Ireversibile cu Viteza Finita. II. Optimizarea puterii utile furnizate de organism, Rev. Chim.(Bucharest), 66, no. 12,2015, p. 2140-2143

4. PETRESCU, S., COSTEA, M., TIMOFAN, L., PETRESCU, V., Means for qualitative and quantitative description of the Cardio-Pulmonary System Operation within Irreversible Thermodynamics with Finite Speed, ASTR Conference, Sibiu, 2014.

5.PETRESCU, S., ENACHE, V., Applying the Finite Speed Thermodynamics (FST) to the Human Cardiovascular System, National Conf. of Thermodynamics (NACOT), Constanta, 2013.

6. HAKEN, H., Advanced Synergetics, Instability Hyerarchies of SelfOrganizing Systems and Devices, (Berlin Heidelberg New York Tokyo: Springer-Verlag) 1983.

7. GEORGESCU, A., Synergetics a new synthesis of science, Bucuresti: Editura Tehnica, 1987.

8. KURAMOTO, Y., Chemical Oscilations, Waves, and Turbulence, (Berlin Heidelberg New York Tokyo: Springer-Verlag) 1984. 
9. Petrescu, S., COSteA, M., Petrescu, A.S., PetresCU, V., BORIARU, N., BOLOHAN, R., BORCILA, B., Processes with Quantum Jumps in the Cardio-Pulmonary System, ASTR Conference, Galati, 2015.

10. Petrescu, S., COSTEA, M., et al., Development of Thermodynamics with Finite Speed and Direct Method, Bucharest, Romania. AGIR, 2011.

11. PETRESCU, S., COSTEA, M., FEIDT, M., GANEA, I., BORIARU, N., Advanced Thermodynamics of Irreversible Processes with Finite Speed and Finite Dimensions, Bucharest, Romania, AGIR, 2015.

12. PETRESCU, S., PETRESCU, V., COSTEA, M., TIMOFAN, L., DANES, S., BOTEZ, G., Discovery of Quantum Numbers In the CardioPulmonary Interaction Studied in Thermodynamics with Finite Speed, Proceedings of ASTR Conference, Sibiu, Romania, 2014.

13. PETRESCU, S., COSTEA, M., PETRESCU, V., BOLOHAN, R., BORIARU, N., PETRESCU, A.S., BORCILA, B., Stationary Quantum States in Cardio-Pulmonary System, ASTR Conference, Galati, Romania, 2015.

14. PETRESCU, S., BOLOHAN, R., PETRESCU, V., BORCILA, B., COSTEA, M., Diagrams Describing Stationary States and Processes in CardioPulmonary System, ASTR Conference, Targu-Mures, 2016.

15. PETRESCU, S., PETRESCU, V., BOLOHAN, R., COSTEA, M., BORCILA, B., Complete Circadian Cycle of Cardio-Pulmonary System Studied in Quantum Biological Thermodynamics with Finite Speed, Proceedings of ASTR Conference, Targu-Mures, 2016.

16. PETRESCU, S., PETRESCU, V., Bolohan, R., BORCILA, B., COSTEA, M., Quantum Biological Thermodynamics with Finite Speed of the Cardio-Respiratory System as a new extension of Thermodynamics with Finite Speed, COFRET 2016 J une 29-30, Proceedings of COFRET'16, Bucharest, Romania, 2016.
17. PETRESCU, S., PETRESCU, V., BOLOHAN, R., BORCILA, B., COSTEA, M., DANES, S., FEIDT, M., BOTEZ, G., HUMINIC, G., HUMINIC, A., BORIARU, N., POPESCU, G., MANITIU N., DUMITRASCU N., PANAITE E., LOZONSCHI T., GHEORGHIAN A., How different we are in terms of Heart-Lung interaction: discovery and description in Quantum Biological Thermodynamics with Finite Speed, COFRET 2016 J une 29-30, Proceedings of COFRET'16, Bucharest, Romania, 2016.

18. PETRESCU, S., BORCILA, B., PETRESCU, V., COSTEA, M., BOLOHAN, $R$., et. al, What is quantum biological thermodynamics with finite speed of the cardio-pulmonary system: a discovery or an invention, Proceedings of Constructal Law \&Second Law Conference, Romanian Academy, Bucharest, 2017.

19. BORCILA, B., PETRESCU, S., COSTEA, M., BOLOHAN, R., PETRESCU, V., BOTEZ, G., Effect of flue on stationary states and processes in the cardio-pulmonary system described in Quantum Biological Thermodynamics with Finite Speed, The 8 the International Conference On Advanced Concepts in Mechanical Engineering, ACME 2018, June 7 - 8, lasi, Romania, 2018.

20. MCCRATY R., ATKINSON M. and TOMASINO D., Science of The Heart, Exploring the Role of the Heart in Human Performance, HeartMath Research Center, Institute of HeartMath, Publication No. 01-001. Boulder Creek, CA, 2001.

21. PETRESCU S., BORCILA B., COSTEA M., PETRESCU V., BOLOHAN R., Quantum Biological Thermodynamics with Finite Speed of the Cardio-Pulmonary System: I- Fundamental Concepts, Equations and Diagrams, Rev. Chim (Bucharest), 70, no. 5, 2019, p. 1561

22. BORCILA B., PETRESCU S., COSTEA M., PETRESCU V., BOLOHAN R., Quantum Biological Thermodynamics with Finite Speed of the Cardio-Pulmonary System: II- Computation of Power and the Entropy Source of the Cardio Pulmonary System, Rev. Chim (Bucharest), 70, no. 6, 2019, p. 1947

$\overline{\text { Manuscript received: } 25.09 .2018}$ 